Mycologia, 99(1), 2007, pp. 112-124.

(C) 2007 by The Mycological Society of America, Lawrence, KS 66044-8897

\title{
Dictyostelids living in the soils of the Atlantic Forest, Iguazú region, Misiones, Argentina: description of new species
}

\author{
Eduardo M. Vadell ${ }^{1}$ \\ Departamento de Biodiversidad y Biología \\ Experimental, 4 piso. II Pabellón, Ciudad \\ Universitaria. FCEN, UBA, Buenos Aires, Argentina \\ James C. Cavender ${ }^{2}$ \\ Department of Environmental and Plant Biology, Ohio \\ University, Athens, Ohio 45701, USA
}

\begin{abstract}
Thirteen new species and varieties of dictyostelid cellular slime molds (csm) were isolated from soils of the Atlantic Subtropical Rain Forest at the Iguazú Falls, Northeastern Misiones Province, Argentina. Seven new species are described herein, one of them is a Polysphondylium, while the rest of the species belong to the genus Dictyostelium. Also, six taxa are new varieties of Dictyostelium and Acytostelium, which will be reported later. Fourteen Northern Hemisphere (Tikal) species have also been isolated from Iguazú soils, some of them new records for Southern South America. This csm community, when compared with others from forests of the Northern Hemisphere, particularly Tikal, Guatemala, give some insight into a possibly different evolutionary history and/or natural selection in the two areas.

Key words: Dictyostelium, Polysphondylium, Southern Hemisphere, Subtropical Atlantic Forest, Taxonomy
\end{abstract}

\section{INTRODUCTION}

Dictyostelid cellular slime molds (csm) were recovered from soils of the Atlantic Subtropical Rain Forest at Iguazú Falls, NE Misiones (25 $28^{\prime}$ S), Argentina during 1995 and 2003 (Vadell 2003, Vadell and Cavender 1995). Seven new undescribed species and 6 new varieties along with 14 other known species and varieties represent the known portion of the community of csm in the soils of the Iguazú forest environment. There are few publications on dictyostelids of the forest soils of the Southern Hemisphere. Cavender (1969) reported the distribution of 9 species in forest soils of East Africa. Hagiwara (1973a) isolated 4 species from soils collected in Papua, New Guinea and the Solomon Islands while Cavender (1976a, b) obtained 14 species and two

Accepted for publication 27 September 2006.

${ }^{1}$ E-mail: eduardo.vadell@gmail.com

${ }^{2}$ E-mail: cavender@ohio.edu.us varieties, 5 of which were new, from subtropical and tropical Southeast Asia. Olive (1975) had reported 3 species from New Zealand, where Stephenson et al (1995) reported 7 species 20 y later. Stephenson et al (1998) recovered one species from the subantarctic Macquarie Island, Southeastern New Zealand. Cavender et al (2002) obtained 13 species, 5 of them new, from the North and South islands of New Zealand $\left(35^{\circ} 16^{\prime}-46^{\circ} 55^{\prime} \mathrm{S}\right)$

Piaggio (1989) reported the distribution of 5 species in Eastern Uruguay. Landolt \& Stephenson (1991) and Cavender (1996) isolated a total of 28 species, 2 of them new (Cavender and Vadell 2000), from different collections from the Amazon basin of Perú. Vadell \& Cavender (1995) and Vadell (2003) first reported on the dictyostelid research at Iguazú, Misiones, Argentina. Also, Vadell (2000) reported 7 species from the southernmost subtropical forest near the estuary of the Rio de la Plata, Punta Lara, in the Province of Buenos Aires, Argentina ( $34^{\circ} 49^{\prime}$ S). A recent survey from the valdivian and Nothofagus forest of Patagonia added six out of nine still undescribed species from the southern colder regions of Argentina, between $40^{\circ}$ and $55^{\circ} \mathrm{S}$ (Cavender et al 2005).

The distributions of most of the new taxa of Iguazú, appear to be confined to the Eastern Atlantic Semievergreen Rain Forest of South America. D. dichotomum, is strongly yellow pigmented, similar to $D$. granulophorum from Tikal (Vadell et al 1995), but has a dichotomous pattern of branching, also seen in $D$. bifurcatum, from Southeast Asia (Cavender 1976a). Among the smaller species, $D$. nanopodium has very small, slightly curved, uniform sorocarps. D. macrocarpum, has narrow spores with consolidated polar granules and ample domed pseudoplasmodia. $D$. vermiformum has small worm-like migrating pseudoplasmodia and prostrate lower sorophores. D. menorah has candelabrum shaped sorogens. D. brevicaule Olive var. brevicaule Vadell et Cavender has stout solitary sorophores and spores with small vesicles. Polysphondylium arachnoideum, the other large species, forms a network of thin terminal segments, almost spider web-like.

\section{MATERIALS AND METHODS}

Study area.-The Iguazú National Park encompasses an area of $550 \mathrm{~km}^{2}$, on the left bank of the Iguazú river, a natural border between Argentina and Brazil. An additional smaller area belonging to the Iguazú Regional 
Park, is located to the west of the horseshoe shaped front of the cascades which are $2.7 \mathrm{~km}$ long and about $70 \mathrm{~m}$ tall. This connects the Iguazú National Park of Argentina and the Iguaçu National Park of Brazil (Bailby 1995). The falls are located at $25^{\circ} 28^{\prime} \mathrm{S}, 56^{\circ} 1^{\prime} \mathrm{W}$. Elevations range from about 50 to $250 \mathrm{~m}$ above the sea level. Soil-forming bedrock is vulcanite, outcropping at the river margin. Soils in the area of Iguazú Falls are mostly lateritic (Bonfils 1970). In some localities there is a warmer microclimate in comparison to the surrounding forest of Misiones and the air is very humid due to the effect of the mist from the cascades. Mean rainfall is $1700 \mathrm{~mm} / \mathrm{y}$ and annual mean temperature is 20$21 \mathrm{C}$. Soils are well drained and rich in organic matter. The litter layer is $3-15 \mathrm{~cm}$ thick. Plant and animal diversity is high. Plant composition is heterogeneous, thus different habitats are found in close proximity. Detailed biogeographical data on these environments can be consulted in Cabrera \& Willink (1982).

Sampling.-Dictyostelid csm described herein were recovered from soil and litter samples as part of Vadell's dissertation research at the University of Buenos Aires. A majority of the sampling was carried out during Apr. 1999; Nov. 2001 and Feb. 2003, with some samples collected on other dates. Four different collecting sites within the Iguazú National Park and Iguazú Regional Park are described below. Plant nomenclature follows the flora of Dimitri (1974). (1) Site I. Upper-lower trails of the Iguazú falls within the National Park. A constant mist is characteristic of this environment with sloping gallery forest. Commonest vascular plant species are Alchornea iricurana, Apuleia leiocarpa, Arecastrum romanzoffianum, Cecropia adenopus, Chusquea ramosissima, Ficus monkii and Chrysophyllum gonacarpum. Elevation varies from 69 to $150 \mathrm{~m}$. Litter layer is not homogeneous in thickness, sometimes with denuded rocks and lateritic soil. Mean soil $\mathrm{pH}$ is 6.5 and $\mathrm{C} / \mathrm{N}=15.7$. (2). Site II. Macuco trail, within the National Park, 2-3 kms. NW from the falls. Commonest tree species are Chrysophyllum gonocarpum, Bastardiopsis densiflora, Inga uruguensis, Machaerium stipitatum, Ocotea diospyrifolia and Luehea divaricata. Elevation varies from 70 to $180 \mathrm{~m}$. Litter is abundant. Mean soil $\mathrm{pH}$ is 5.8 and $\mathrm{C} / \mathrm{N}=14.9$. (3). Site III. Yacaratia trail, $4-5 \mathrm{kms}$. NW of the falls. Commonest tree species are Aspidosperma polyneuron, Cabralea oblongifolia, Nectandra megapotamica, Ocotea diospyrifolia, Lonchocarpus muehlbergianus, Cedrela fissilis and Tabebuia ipe. Elevation varies from 250 to below $200 \mathrm{~m}$. Litter is abundant. Mean soil $\mathrm{pH}$ is 6.6 and $\mathrm{C} / \mathrm{N}=11.3$. (4) Site IV. Yry-apú trail, which is along a $60 \mathrm{~km}^{2}$ area $10 \mathrm{~km} \mathrm{NW}$ of the falls, within the Iguazú Regional Park. The aboriginal people, Mbyá Guaraní, inhabit this enviroment. Commonest tree species are Aspidosperma polyneuron, Diatenopteryx sorbifolia, Parapiptadenia rigida, Patagonula americana, Cabralea oblongifolia, Inga uruguensis. Soils are mostly lateritic with variable litter deposition. Mean $\mathrm{pH}$ is 6.2. Elevation is $180 \mathrm{~m}$ above sea level. Sites II, III and IV are fairly pristine; Site I has some anthropogenic disturbances.

Sample processing.- Samples of $20 \mathrm{~g}$ of surface humus and litter were collected in plastic bags, and stored within a cooler. Twenty of the collected samples were processed from each of the four described environments. Samples were plated out on dilute hay infusion agar media in the laboratory according to the Cavender's isolation technique (Cavender and Raper 1965). Clones of each species were identified and presumptive new taxa were isolated and inoculated on agar media in a two membered culture with Escherichia coli $\mathrm{B} / \mathrm{r}$, under diffuse light and at different controlled temperatures. Each one of the cultures was observed every day for aggregation, pseudoplamodia and sorocarp formation and data were collected progressively. The clones recovered were studied, identified, drawn, photographed and described. Taxonomic nomenclature follows that of Raper (1984). The optical equipment used were a Bauch \& Lomb dissecting microscope, an Olympus compound phase contrast microscope, a Stemy SR Zeiss and Reichert dissecting lenses. Spores, myxamoebae and sorophores of different clones were suspended in Bonner's salt solution (Bonner 1947) for measurements under the microscope. All clones of taxonomic value were lyophilized and deposited in the BAFC (Buenos Aires Facultad de Ciencias) Culture Collection of the University of Buenos Aires and in the Kenneth B. Raper CSM Collection at Ohio University. New species were sent to the American Type Culture Collection, Manassas Virginia,

\section{RESULTS}

Dictyostelium macrocarpum Vadell et Cavender sp. nov. $\quad$ Figs. 1A-C, 2A-H.

Sorocarpia culta in agaro nonnutricio cum Escherichia coli ad 12-26 C solitaria vel fasciculata, prona, irregulariter ramosa parvaque. Sorophora sinuosa, prostrata, 1-2.8 $\mathrm{mm}$ longa. Sorophora irregularia, gradatim attenuata e basibus multicellaribus ad apices $(8-10 \mu \mathrm{m})$. Praesertim sorophora infra apices unicellulares nata sunt. Bases rotundae vel claviformes (15-20 $\mu \mathrm{m}$ diametro). Bases inclusa in capsula mucosa. Sori albo-hyalini, irregulariter globosi (80-200 $\mu \mathrm{m}$ diam.). Sporae ellipticae vel reniformes, angustae breves; granulis consolidatis polaribus et subpolaribus, regulares, 4-6 (-6.5) × 2-3 $\mu \mathrm{m}$ (dimidium 5.10 $\times 2.2 \mu \mathrm{m})$. Aggregatio prismo tholiformis vel tumuliformis, dein irregularis rivulis brevibus dendroides regularibus. Aggregationes partitae, centris secundariis minoribus sorogena solitaria factis; aggregationes majores 1-2 $\mathrm{mm}$ in diam., minores rarissime rivulis. Sorogena praecocia usque ad $1 \mathrm{~mm}$ longa, plerumque vermiformia, recurvata, regularia in diam., sinuosa; serotina longissima. Saepe sorogena elongata et vermiformia(1 mm). Myxamoebae parvulae, 1-2 vacuolis.

Sorocarps solitary to tightly clustered (FIGs. 1C, 2C), 1-2.8 mm high, in general irregularly branched in aged cultures, sigmoid, prone, mostly with prostrate lower sorophores, when cultivated on nonnutrient agar with Escherichia coli at 22-26 C (FIG. 2H). Sorophores unevenly tapered from expanded bases to 

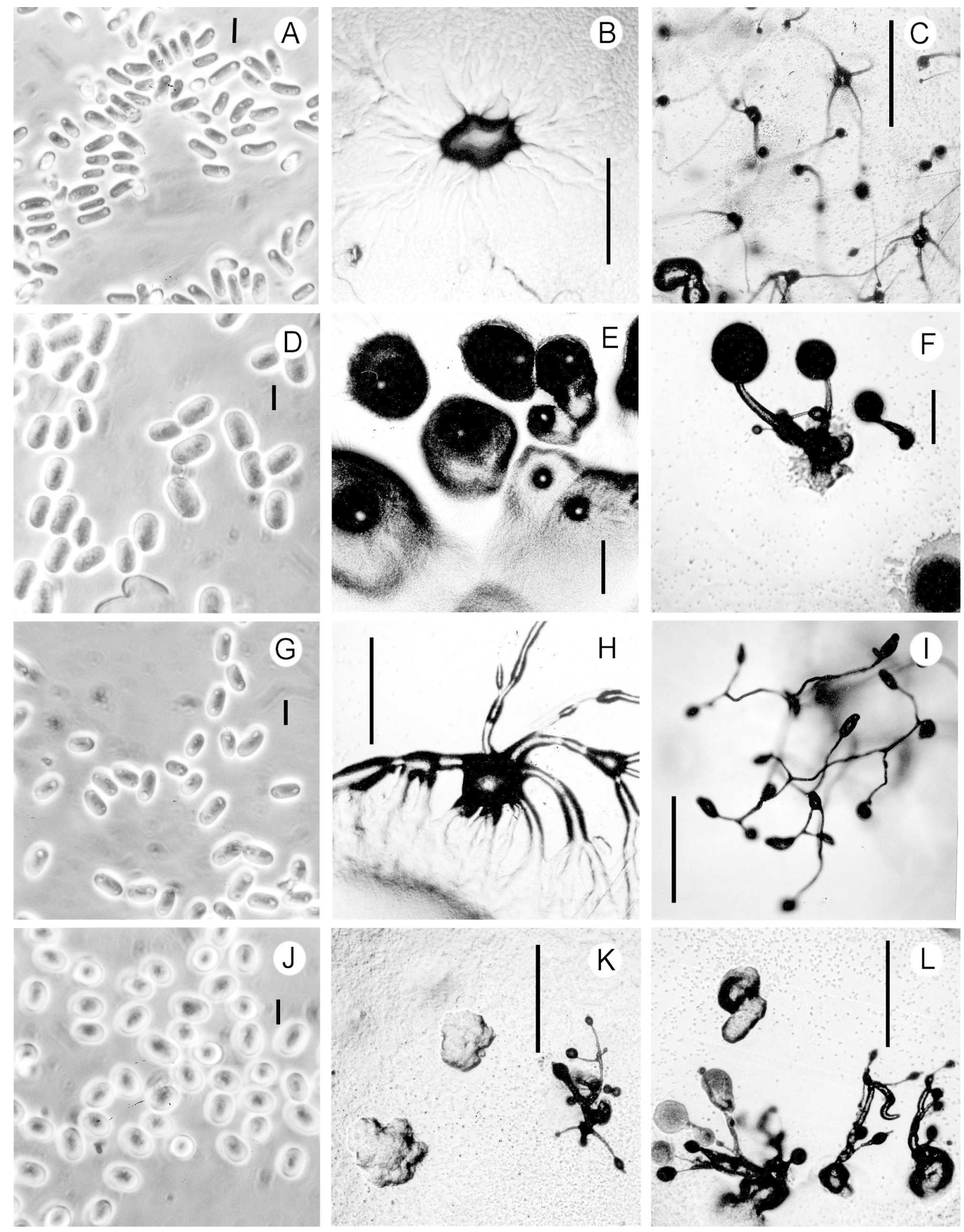

Fig. 1. Features of Dictyostelium species from Iguazú. A-C. D. macrocarpum. A. Elliptical-reniform spores with consolidated granules. B. Ample dome-like aggregation. C. Clustered sorocarps. D-F. D. D. brevicaule. D. Elliptical spores with sparse vesicles. E. Late aggregations and developing sorogens. F. Unbranched stout sorocarps. G-I. D. dichotomum. G. Ellipticaloblong spores with irregularly distributed consolidated and unconsolidated granules. H. Large aggregation with secondary 
tips. Terminal segment generally of one tier of cells. Tips capitate, regular, 8-10 $\mu \mathrm{m}$ diam (FIG. 2E). Bases slightly globoid to clavate, $15-20 \mu \mathrm{m}$ diam, within a mucilaginous capsule (FIG. 2D). Sori white-hyaline, globose, irregular, 80-200 $\mu \mathrm{m}$ diam. Spores elliptic to reniform, narrow, 4-6 $(-6.5) \times 2-3 \mu \mathrm{m}$, and $5.10 \times$ $2.2 \mu \mathrm{m}$ on average; very regular in size and shape, with consolidated polar to subpolar granules (FIGs. 1A, 2G). Aggregation dome or mound-like at first, as a flattened globule, then becoming irregular and developing dendroid short regular streams (Figs. 1B, 2A). Aggregations partite; secondary smaller centers of aggregation will develop into solitary sorogens. Larger aggregations: 1-2 $\mathrm{mm}$ in diam. (FIGS. 1B, 2A), the smaller rarely streaming. Early sorogens up to $1 \mathrm{~mm}$ in length (FIG. 2B), generally vermiform, recurved, regular in diam., sinuose (FIG. 2B, C). Late sorogens very elongated (FIG. 2C). Myxamoebae small, 1-2 vacuolate (FIG. 2F).

Commentary. The characteristic "honey drop" or dome-like shape of the early pseudoplasmodia which become massive and irregular is a distinguishing characteristic as well as the clustered sorocarps and small narrow $\mathrm{PG}+$ spores.

Etymology: macrocarpum, referring to the ample and massive pseudoplasmodia.

Habitat and distribution. The species has been isolated from Macuco trail, Yacaratia and Yry-apú trails, Sites II, III and IV. In Macuco, in slightly acidic soil ( $\mathrm{pH}$ 5.7, elevation $100 \mathrm{~m}$ ).

Cultures examined. ARGENTINA, MISIONES: Iguazú National Park, Macuco trial, $25^{\circ} 28^{\prime}$ S, $56^{\circ} 1^{\prime}$ W, elevation $100 \mathrm{~m}$. Isolate MGE2 from soil-litter, 8 Mar 2003, Cavender No. 8 12Y4, BAFC 1099 (HOLOTYPE), present in very pristine areas of Iguazú. Other isolations from Yacaratia trail and Yry-apú trail were observed but not preserved.

\section{Dictyostelium brevicaule Olive var. brevicaule Vadell} et Cavender sp. nov.

Figs. 1D-F, 3A-I

Sorocarpia culta in agaro nonnutricio cum Escherichia coli ad 18-25 C, solitaria aut bifasciculata; erecta vel prona, rarissime ramosa parvaque e bases. Sorophora 1-3 mm longa, leve phototropica. Sorophora alba, leve curva per gradatim attenuata e basibus dilatatas ad apices. Apices capitates (3-10 $\mu \mathrm{m}$ diam.). Bases rotundae, irregularia, ampla, saepe in plana termina (40-90 $\mu \mathrm{m}$ diam). Sori albo-hyalini, globosi (100-340 $\mu \mathrm{m}$ diam.). Sporae e ellipticae vel ovalis, saepe vesiculis, saepe $6-7.5(-7.8) \times 3-4.2 \mu \mathrm{m}$,

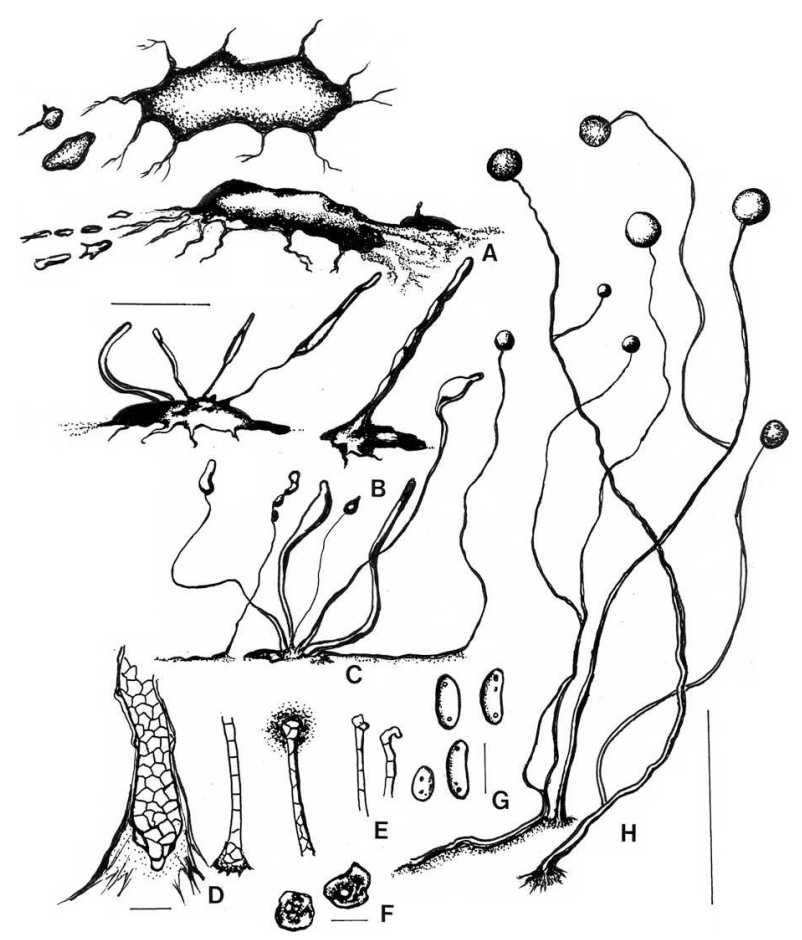

FIG. 2. Dictyostelium macrocarpum. A. Ample dome-like aggregations. B. Early sorogens. C. Late sorogens. D. Clavate irregular base. E. Capitate to curved tips. F. Small myxamoebae. G. Elliptical to reniform spores with consolidated polar to subpolar granules. H. Mature sorocarps. Bars: A-C, $\mathrm{H}=0.3 \mathrm{~mm} ; \mathrm{D}, \mathrm{E}=15 \mu \mathrm{m} ; \mathrm{G}, \mathrm{F}=5 \mu \mathrm{m}$.

et in dimidium $6.8 \times 3.3 \mu \mathrm{m}$. Capsula sporii partitae per symmetrica aequalia partes separant in angulo e 80 ad $90^{\circ}$, hiatus interpolaris rectis formae; alter nexus ad termina. Aggregationes ad classem "mucoroides" pertinentes, $500-1000 \mu \mathrm{m}$. Sorogena vermiformia $(50-200 \mu \mathrm{m})$, interdum abnormes. Myxamoebae saepe $2-3$ vacuolis, $8-12 \times 5-7 \mu \mathrm{m}$.

Sorocarps solitary, sometimes in loose clusters of 23 (FIG. 1F), erect, stout and rigid, slightly phototropic, 1-3 mm high, sometimes with short branches at or near the base, when cultivated on nonnutrient agar with E. coli at 18-25 C (Figs. 1F,3C, I). Sorophores strongly tapered from expanded slimy bases to tips, slightly recurved (FIG. 1F). Tips capitate, 3-10 $\mu \mathrm{m}$ diam (FIG. 3E). Bases round to globoid, irregularly expanded, sometimes with a plane end, 40-90 $\mu \mathrm{m}$ diam (FIG. 3D). Sori globose, 100-340 $\mu \mathrm{m}$ diam., hyaline-white. Spores elliptic-ovoid, 6-7.5 $(-7.8) \times$ $3-4.2 \mu \mathrm{m}$, and $6.8 \times 3.3 \mu \mathrm{m}$ in average; with vesicles

$\leftarrow$

lobular centers and ample streams. I. Dichotomous architecture of developing sorocarp. J-L. D. menorah. J. Oblong-elliptical spores with dispersed consolidated granules. K. Small aggregations with developing sorocarps. L. Typical candelabrum-like architecture of the sorocarps. Bars: A, D, G, J $=5 \mu \mathrm{m}$; E, F $=0.5 \mathrm{~mm}$; B, C, H, L= $0.5 \mathrm{~mm}$. 


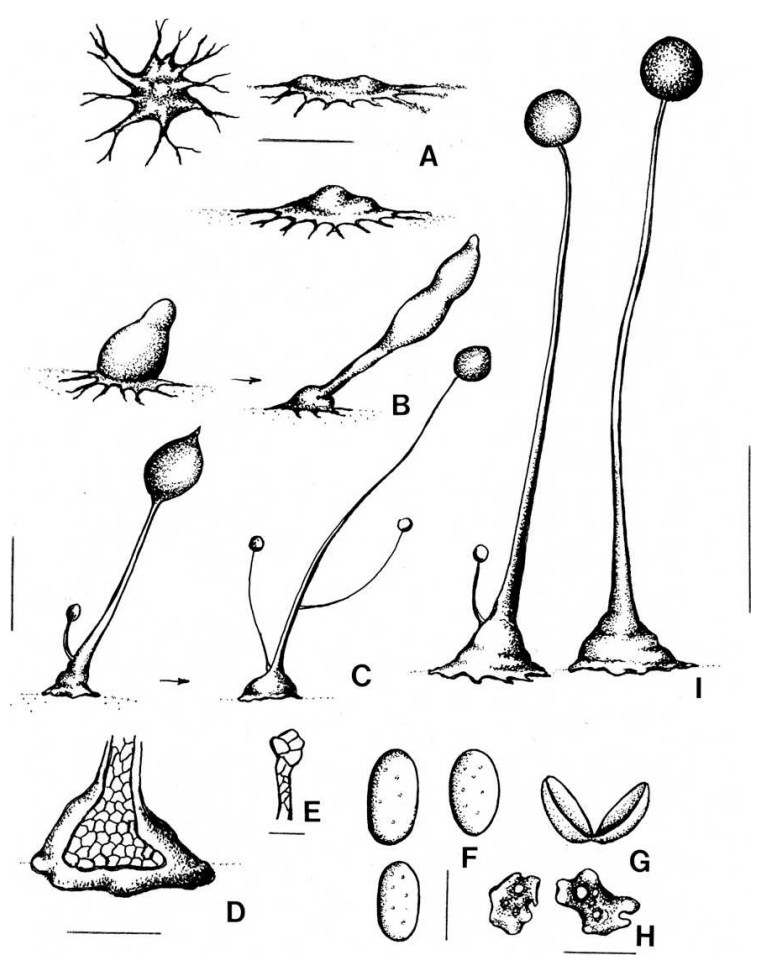

FIG. 3. Dictyostelium brevicaule. A. Aggregation. B. Early sorogens. C. Late branched sorogen and sorocarp. D. Rounded irregular base. E. Capitate tip. F. Elliptical-oblong spores with vesicles. G. Spore case. H. Myxamoebae. I. Solitary stout sorocarps, one of them with a lower short branch. Bars: A $=0.5 \mathrm{~mm} ; \mathrm{B}, \mathrm{C}, \mathrm{I}=1 \mathrm{~mm} ; \mathrm{D}=35 \mu \mathrm{m} ; \mathrm{E}, \mathrm{F}$, $\mathrm{G}=6 \mu \mathrm{m} ; \mathrm{H}=10 \mu \mathrm{m}$.

(FIGS. 1D, 3F). Spores dehisce longitudinally leaving two symmetrical spore-case halves attached to one of the spore ends, at an angle of $80^{\circ}-90^{\circ}$ (FIG. 3G). Aggregation of the "mucoroides" type, 500-1000 $\mu \mathrm{m}$ diam. (FIGS. 1E, 3A). Sorogens vermiform, sometimes peanut shaped (FIG. 3B). Myxamoebae 2-3 vacuolated, $8-12 \times 5-7 \mu \mathrm{m}$ (FIG. 3H).

Commentary. This species resembles that of Olive (1901) in one important respect, e.g. the short sorophore.

Etymology: brevicaule, referring to the short height of the sorocarps.

Habitat and distribution. Isolated from soil-litter at all environments searched in the Iguazú, both Regional and National Parks, presumptively common within the region from Aug to Mar (soil pH range 5.86.6, elevation range $100-250 \mathrm{~m}$ ).

Cultures examined. ARGENTINA, MISIONES: Iguazú Regional Park, Yry-apú trail, $25^{\circ} 28^{\prime}$ S, 56 $6^{\circ} 1^{\prime}$ W, elevation $180 \mathrm{~m}$. Isolate from soil-litter, 20 Aug 1999, Vadell No. 1049YA17, BAFC 955 (HOLOTYPE) and ARGENTINA, MISIONES, Iguazú National Park, Site I, Upper-Lower trail, 26 Sept 1995, Vadell No. 1051CC8, BACF 957; Macuco trail, 15 Nov 2001, Vadell No. 1105M4, BACF 1127; Yacaratia trial,

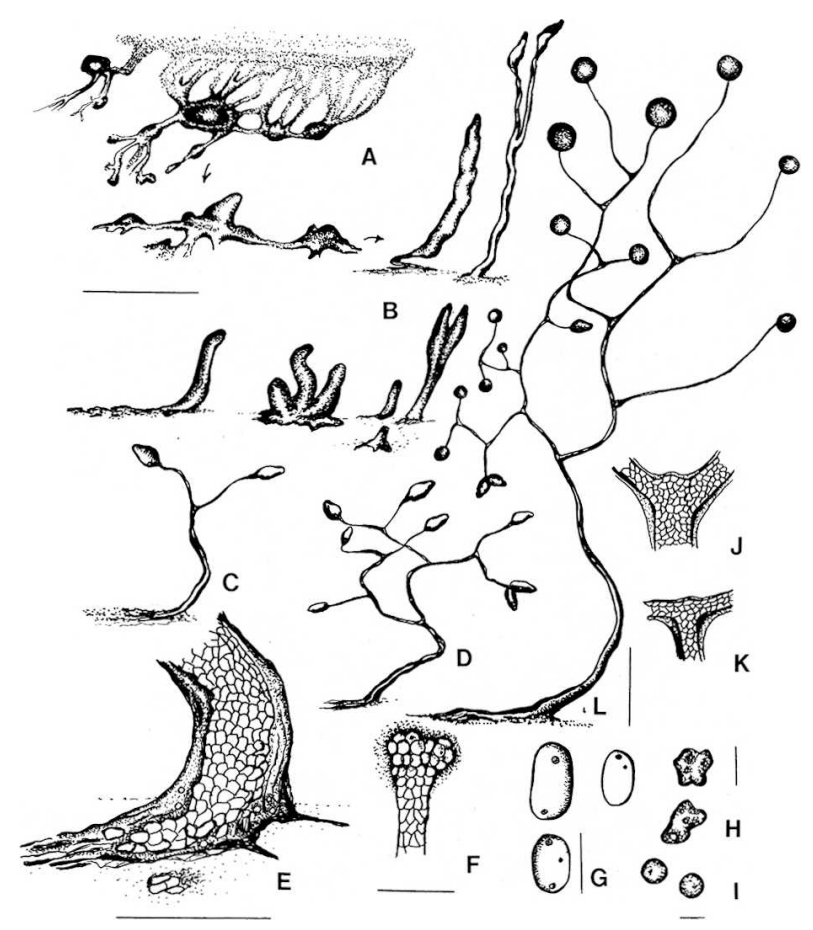

FIG. 4. Dictyostelium dichotomum. A. Aggregation of the violaceum type. B. Early sorogens. C-D. Sequence of development of forks in late sorogens. E. Clavate amorphous base. F. Compound capitate tip with matrix of dense slime. G. Elliptical- oblong spores with mostly consolidated polar and unconsolidated dispersed granules. H. Myxamoebae. I. Microcysts. J, K. Angles of forks at branches. L. Mature sorocarp. Bars: A-C $=0.5 \mathrm{~mm}$; E, F, J, K, L = $30 \mu \mathrm{m}$; $\mathrm{G}=6 \mu \mathrm{m} ; \mathrm{H}=10 \mu \mathrm{m} ; \mathrm{I}=4 \mu \mathrm{m}$.

8 Mar2003, Cavender No. 4 4Y3, BACF 1158. Also isolated from soils of Puerto Canoas, Iguazú National Park in Feb 2001.

Dictyostelium dichotomum Vadell et Cavender sp. nov. FIGS. 1G-I, 4A-L.

Sorocarpia culta in agaro nonnutricio cum Escherichia coli ad 20-21 C solitaria vel fasciculata, prona vel erecta, iterum cum ramae aequaliter bifurcata, e semel ad quatuor, similaris ad dichotomico concepto, intense lutei, $0.6-2.5 \mathrm{~mm}$ longa (dim. $1.3 \mathrm{~mm}$ ), phototropica. Sorophora lutei, irregularia: sorophora supra bases saepe prostrata, curva et prona. Apices capitates (15-25 $\mu \mathrm{m}$ diam.). Bases irregularia, ampla, saepe prostrata, e clavatae ad abnormes. Sori palluslutei, globosi ( $80 \mu \mathrm{m}$ diam.). Sporae e ovalatae ad ellipticae, granulis consolidatis polaribus et subpolaribus, saepe coalescens, 4-6 (-6.5) × 2-2.5-3.5 $\mu \mathrm{m}$ (dim. $5.1 \times 2.9 \mu \mathrm{m})$. Aggregationes ad classem "violaceum" pertinentes, abnormes, lutei, 0.6$2.5 \mathrm{~mm}$, varia in diametro e alter breviter radiatae ad 250-500 $\mu \mathrm{m}$. Sorogena vermiformia, saepe bifur- 
catae, lutei, 0.3-1 mm longa, interdum abnormes. Myxamoebae breves et pallus.

Sorocarps solitary to clustered, sinuose, erect to prone, dichotomously branched (FIGS. 1I, 4D, L), intense yellow pigmentation, $0.6-2.5 \mathrm{~mm}$ (average $1.3 \mathrm{~mm}$ ) in length, phototropic, when cultured at 20$21 \mathrm{C}$ on nonnutrient agar with E. coli. Sorophores uneven, with clavate amorphous bases (FIG. 4E) (range 10-40 $\mu \mathrm{m}$ ), sometimes unfinished, and within a dense matrix of slime, and compound capitate tips (FIG. 4F) (range 15-25 $\mu \mathrm{m}$ ). Lower sorophore generally prostrate, curved and inclined. Sorophore architecture may show up to 4 successive forks. Sori globose, intense yellow, 30-150 $\mu \mathrm{m}$ (average $80 \mu \mathrm{m}$ ) diam. Spores oblong-elliptical, yellow, with prominent polar to subpolar granules, mostly consolidated, 4-6 $(-6.5) \times 2-2.5-3.5 \mu \mathrm{m}$ (average $5.1 \times 2.9 \mu \mathrm{m})$ (Figs. 1G, 4G). Myxamoebae small and yellow (FIG. $4 \mathrm{H})$. Large aggregations are of the violaceum type, irregular, intense yellow, with lobular secondary centers of aggregation and ample streams (FIGS. 1H, 4A) (range $0.6-2.5 \mathrm{~mm}$ ). Small aggregations radiate (range $0.25-0.5 \mathrm{~mm}$ ). Early sorogens vermiform, very elongated and sometimes bifurcated (FIG. 4B) (300$1000 \mu \mathrm{m})$.

Commentary. Early sorogens may migrate briefly (FIG. 4B left). Angles of bifurcation vary from nearly $180^{\circ}$ to $90^{\circ}$ (FIG. 4J, K). Intense yellow color of pseudoplasmodia, sorogens and sorocarps, when cultivated in darkness; slowly fades with continuous cultivation under diffuse light. Some strains produce microcysts (FIG. 4I). Below or above optimal temperatures sorocarps may not be dichotomous, or may branch irregularly.

Etymology: dichotomum referring to the dichotomous pattern of branching.

Habitat and distribution. Isolated from soil-litter of Macuco trial, Iguazú National Parks (soil pH 5.8, elevation $100 \mathrm{~m}$ ), and also from the soil-litter surrounding the Jesuitic ruins of Loreto, Misiones, Argentina (Vadell \& Cavender 1995, Vadell 2003).

Cultures examined. ARGENTINA, MISIONES: Iguazú Regional Park, Yry-apú trail, $25^{\circ} 28^{\prime}$ S, 56 $6^{\circ} 1^{\prime} \mathrm{W}$, elevation $180 \mathrm{~m}$. Isolate from soil-litter, 20 Aug 1995, Vadell No. 878M9, BAFC 51182 and ARGENTINA, MISIONES, Iguazú National Park, Macuco trail, 15 Feb 2003, Vadell No. 1167M6, BAFC 834 (HOLOTYPE); Iguazú National Park, Macuco trail, Aug 1995, Vadell No. 812IGM8, BAFC 51182. ARGENTINA, MISIONES, Loreto $\left(27^{\circ} 19^{\prime} \mathrm{S}, 55^{\circ} 31^{\prime}\right.$ W), Aug 1995, Vadell No. 866L9, BAFC 51157.

Dictyostelium menorah Vadell et Cavender sp. nov. Figs. 1J-L, 5A-K.

Sorocarpia culta in agaro nonnutricio cum Escherichia coli ad 20-21 C solitaria vel fasciculata, erecta,

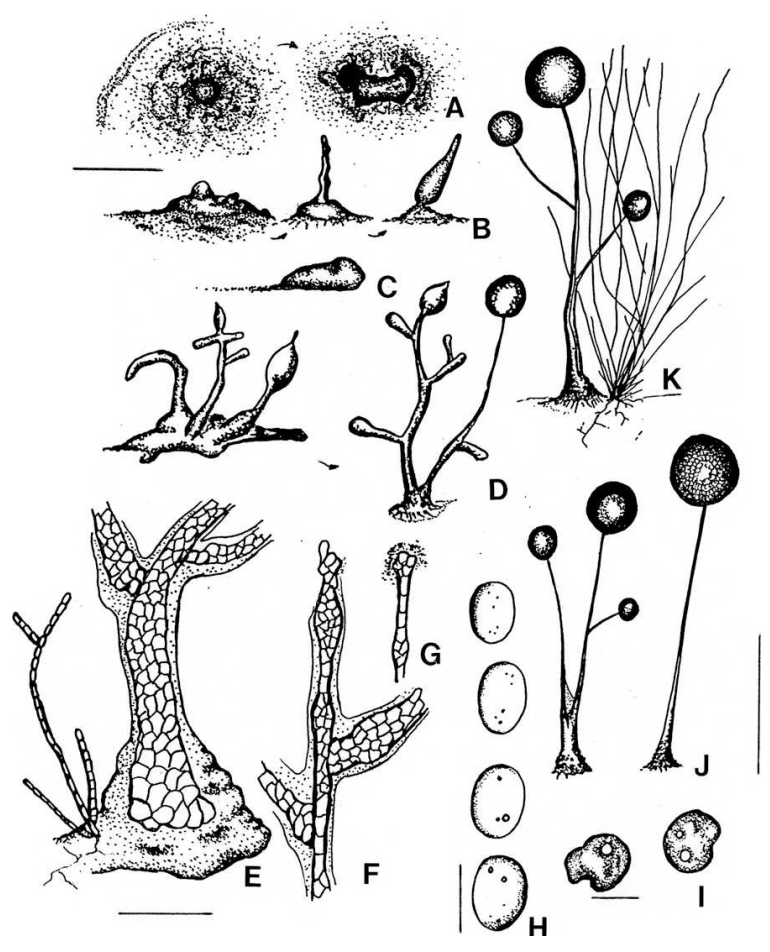

FIG. 5. Dictyostelium menorah. A. Small mound-like aggregations. B. Developing sorogens. C. Migrating pseudoplasmodium with an Actinomycete associate. D. Clustered early (left) and late (right) branched sorogens. E. Round to clavate base. F. Detail of branch and its base. G. Compound capitate tip. H. Oblong-elliptical spores with dispersed consolidated granules. I. Small myxamoebae. J. Mature fruiting body. Sorocarp with associated Actinomyces sp. Bars: A, B, C, D = $0.2 \mathrm{~mm}$; E, F, G $=15 \mu \mathrm{m}$; H $=5 \mu \mathrm{m}$; I $=10 \mu \mathrm{m} ; \mathrm{J}, \mathrm{K}=200 \mu \mathrm{m}$.

ramosa, e 350 ad $550 \mu \mathrm{m}$ longa (dim. $400 \mu \mathrm{m}$ ). Praesertim sorophora irregularia; infra apices unicellularibus nata sunt. Apices grandes, capitates (10$15 \mu \mathrm{m})$, saepe amorpha et flexuosis, inclusa in vagina dilatata. Bases rotundae vel claviformes $(20-25 \mu \mathrm{m}$ diam.) aut geometrica plana termina, inclusa in capsula mucosa et granulosa. Ramae breves et sustentatio parvaque. Sori hyalini, globosi $(-70 \mu \mathrm{m}$ diam.). Sporae e ovalis ad ellipticae, granulis consolidatis polaribus, saepe bipolaribus, dispersa, saepe $5-7(-7.5) \times 3-4.8 \mu \mathrm{m}($ dim. $5.4 \times 3.7 \mu \mathrm{m})$. Aggregationes tipi cumuli parvuli, irregulares, $200 \mu \mathrm{m}$ diam. Breviter sorogena praecox migrans. Provecta sorogena fasciculata, ramis similaris manis forma. Myxamoebae breves, $1-2$ vacuolis, saepe $9 \times 7 \mu \mathrm{m}$.

Sorocarps solitary to clustered, erect, generally branched, 350 to $550 \mu \mathrm{m}$ high (average $400 \mu \mathrm{m}$ ) (FIGS. 1K, L; 5J). Sorophores generally uneven, terminating in one tier of cells, when cultivated on nonnutrient agar with $E$. coli at 20-21 C. Tips compound capitate $(10-15 \mu \mathrm{m})$, sometimes unfinished and curved, surrounded by dense slime 
(FIG. 5G). Bases round to clavate, 20-25 $\mu \mathrm{m}$ in diam., with a plane end (FIG. 5E), and covered with abundant granular dense slime. Branches uneven (50-100 $\mu \mathrm{m}$ length), with small basal attachment (FIG. 5F). Sori globose, hyaline, 40-70 $\mu \mathrm{m}$ diam., with distinguishable spores. Spores oblong-elliptical, with some dispersed consolidated granules, mostly at poles (range 5-7(-7.5) $\times 3-4.8 \mu \mathrm{m}$; average $5.4 \times 3.7 \mu \mathrm{m}$ ) (Figs. 1J, 5H). Aggregations: small mounds, irregular in shape (average $200 \mu \mathrm{m}$ ) (FIGS. 1K, 5A). Early sorogens may migrate briefly. Late sorogens are in clusters and show typical pattern of branching (Figs. 1L, 5D). Myxamoebae small. 1-2 vacuolated, mostly $9 \times 7 \mu$ m (FIG. 5I).

Commentary. This species grows and develops well along with Actinomyces spp colonies of the same size, which appear to buffer the hydric requirements of this small dictyostelid (FIG. 5K). Observations suggest a possible synergism between these two organisms. When cultivated on hay infusion agar and below $20 \mathrm{C}$, sorogens tend to emerge tightly clustered.

Etymology: menorah, referring to sorocarps that resemble the artcraft lines or architecture of a Jewish candelabrum.

Habitat and distribution. Soil-litter of Macuco trail (pH 6), Iguazú National Park Misiones, Argentina.

Cultures examined. ARGENTINA, MISIONES: Iguazú National Park, Macuco trail, $25^{\circ} 28^{\prime} \mathrm{S}, 56^{\circ} 1^{\prime} \mathrm{W}$, elevation $180 \mathrm{~m}$. Isolate from soil-litter, $20 \mathrm{Feb}$ 2003, Cavender No. 38M1, BACF 1131 (HOLOTYPE).

Dictyostelium nanopodium Vadell et Cavender sp. nov. Figs. 6A-C, 7A-K.

Sorocarpia solitaria culta in agaro nonnutricio cum Escherichia coli ad 22-26 C, interdum fasciculata, remisse, $0.25-0.65 \mathrm{~mm}$ long., praesertim non ramosa, erecta vel prona, non phototropica, regularia et aequalis a dimentionem. Sorophora per gradatim attenuata e dilatata bases ad apices $(5-9 \mu \mathrm{m})$, breves, leve curva vel recta, praesertim cum inferior unicellularis apices partes. Apices simple vel capitates (5$9 \mu \mathrm{m}$ diam.). Bases rotundae interdum discoidea formae, (10-25 um diam.). Sori albo-luteoli, globosi, irregularia (30-70 $\mu \mathrm{m}$ diam.). Sporae e ellipticae ad reniformes, 4.5-6.5 $(-6.7) \times 2.5-3 \mu \mathrm{m}(\operatorname{dim} .5 .6 \times$ $2.9 \mu \mathrm{m}$ ), granulis consolidatis subpolaribus, iregulares et mox germinationem. Aggregationes cumula parvulae format, irregulares $(100-300 \mu \mathrm{m})$, rarissime radiatae. Sorogena saepe vermiformia vel curva. Myxamoebae saepe $2-3$ vacuolis, 7-20 × 10-25 $\mu \mathrm{m}$. Microcystae praesentes, media magnitude $4 \mu \mathrm{m}$.

Sorocarps solitary, sometimes in loose clusters, $0.25-0.65 \mathrm{~mm}$ high, generally unbranched, erect to prone, non phototropic, even and regular in size, when cultivated on nonnutrient agar with $E$. coli at
22-26 C (Figs. 6C, 7K). Sorophores tapered from expanded bases to tips, straight or slightly curved. Terminal segment of sorophores generally of one tier of cells. Tips simple to capitate, $5-9 \mu \mathrm{m}$ diam (FIG. 7G). Bases globoid or round, sometimes disk-shaped, 10-25 $\mu \mathrm{m}$ diam. (FIG. 7F). Sori globose, irregular, mostly 30-70 $\mu \mathrm{m}$ diam., white-cream. Spores elliptical to reniform, 4.5-6.5 (-6.7) $\times$ 2.5$3 \mu \mathrm{m}$ (average $5.6 \times 2.9 \mu \mathrm{m}$ ), with consolidated subpolar granules, irregular in shape and size (FIGS. 6A, 7I). Spores germinate immediately. Aggregation is mound-like, irregular, $100-300 \mu \mathrm{m}$ (FIGS. 6B, 7A), rarely streamed. Early sorogens synchronous when clustered and briefly migrating when solitary (FIG. 7B, C); vermiform, uncinate or recurved (FIG. 7D), sometimes bifid (FIG. 7E). Myxamoebae 23 vacuolate, $7-20 \times 10-25 \mu \mathrm{m}$ (FIG. $7 \mathrm{H})$. Microcysts: $4 \mu \mathrm{m}$ (in average) (FIG. 7J).

Commentary: This small species is very uniform in height and keeps its sorocarps erect holding the viable sori for a long time.

Etymology: nanopodium, referring to the minute sorocarps.

Habitat and distribution. Dry soil-litter of Site I, Upper-lower trail (pH 6.3), Iguazú National Park, Misiones, Argentina, in 2001 and from soil-litter (pH 6.2) of Site II, Yry-apú area in 2003.

Cultures examined. ARGENTINA, MISIONES: Iguazú National Park, Upper-lower trail, $25^{\circ} 28^{\prime} \mathrm{S}, 56^{\circ} 1^{\prime} \mathrm{W}$, elevation $150 \mathrm{~m}$. Isolate from soil-litter, 15 Aug 2001, Vadell No. 1033CS6, BACF 951 (HOLOTYPE) and ARGENTINA, MISIONES, Iguazú Regional Park, Yry-apú trail, 10 Aug 2001, Vadell No. 1036YA24, BAFC 708 and Feb 2003, Vadell No. 1037YA 25, BAFC 1042.

Dictyostelium vermiformum Vadell et Cavender sp. nov. Figs. 6D-F, 8A-J.

Sorocarpia culta in agaro nonnutricio cum E. coli ad 20-22 C solitaria vel fasciculata, erecta vel prostrata, rarissime ramis parvaque, saepe $0.6-1.5 \mathrm{~mm}$, rarissime supra $2 \mathrm{~mm}$ longa. Sorophora supra base prostrata, dein erecta, non phototropica. Sorophora gradatim attenuata e basibus multicellularibus ad apices, involuta in vagina irregulare et infra apicibus unicellularibus partes. Apices capitates vel amorphus $(8-15 \mu \mathrm{m})$. Bases breves, rotundae $(8-20 \mu \mathrm{m}$ diam.). Bases inclusa in capsula mucosa. Sori albo-hyalini, globosi aut ovi formae $(60-120 \mu \mathrm{m}$ diam.). Sporae e ovalatae ad ellipticae, irregulares breves, saepe grandis granulis consolidatis alii dispersa alii parvula vel nulla, saepe $4.5-8(-8.3) \times 2.0-4.5 \mu \mathrm{m}(\operatorname{dim} .5 .8 \times$ $3.0 \mu \mathrm{m})$. Aggregationes ampla aut anastomosae rivulis $(400-500 \mu \mathrm{m})$. Ergo, praecox sorogena e cumula, coronae formant. Provecta sorogena velox, vermiformia et cum posterum non-connexus parvi corpora. 


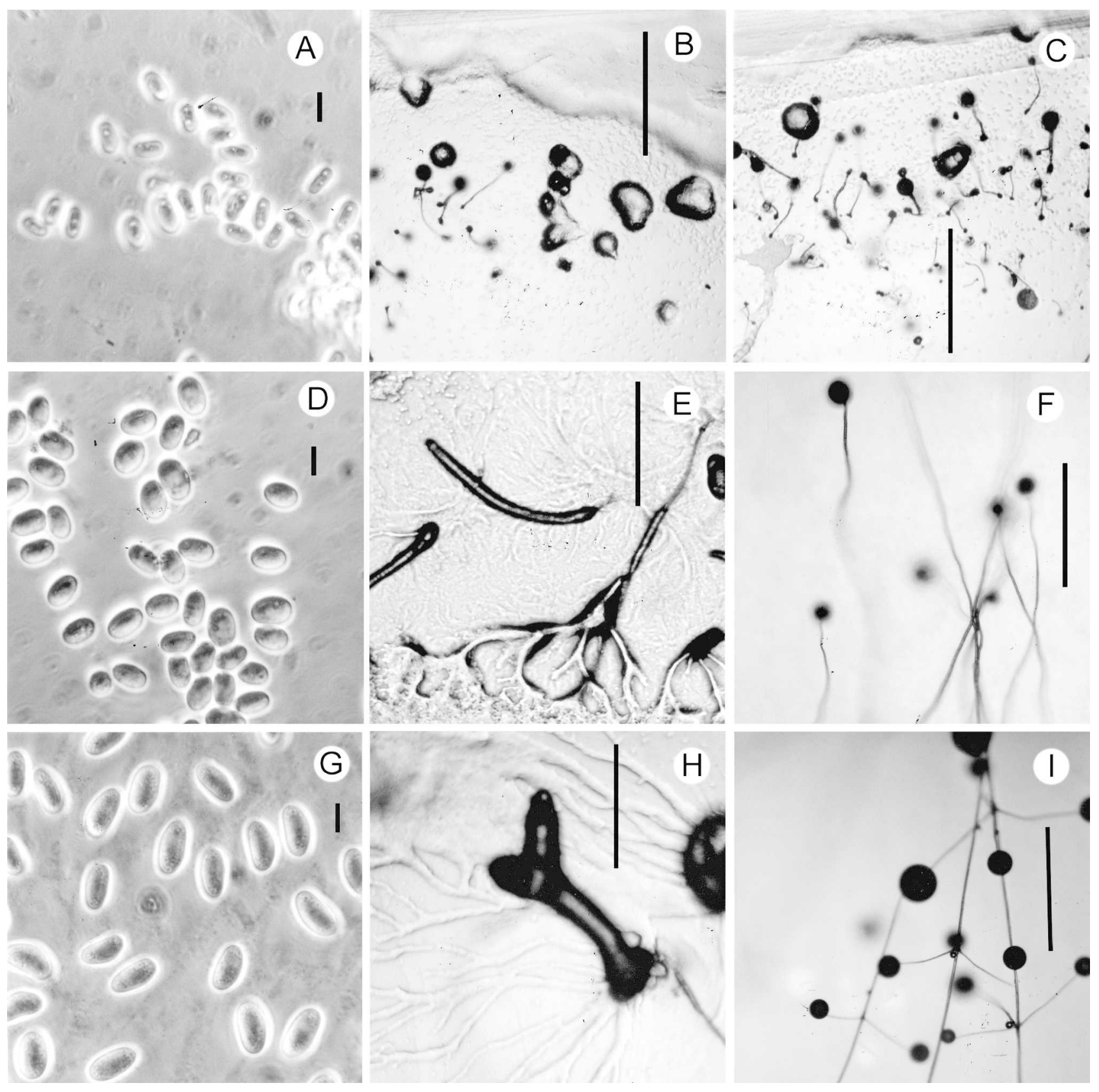

Fig. 6. Features Dictyostelium and Polysphondylium species from Iguazú. A-C. D. nanopodium. A. Elliptical spores with subpolar granules. B. Mound aggregations and sorocarps. C. Mature sorocarps. D-F. D. vermiformum. D. Oblong-elliptical spores with small granules. E. Late aggregation with vermiform sorogens. F. Mature curved sorocarps with prostrate lower sorophores. G-I. P. arachnoideum. G. Elliptical spores with unconsolidated polar granules. H. Forked sorogen and remains of a late aggregation. I. Portions of whorled sorocarps with recurved branches. Bars: A, D, G= $5 \mu \mathrm{m} ; \mathrm{B}, \mathrm{C}, \mathrm{E}, \mathrm{F}, \mathrm{H}, \mathrm{I}=0.5 \mathrm{~mm}$.

Sorogena vermiformia longissima, libera et migrantes. Myxamoebae migrantes extra bacteriae substratum.

Sorocarps solitary to clustered, erect, sometimes prostrate or becoming decumbent, rarely branched, $0.6-2 \mathrm{~mm}$, rarely more and commonly not over $1.5 \mathrm{~mm}$ in length, when cultivated on nonnutrient agar with E. coli at 20-22 C (Figs. 6F, 8H, I). Lower sorophore prostrate, then prone, when not erect (FIG. $8 \mathrm{H}$ ). Sorophore tapered from expanded bases to tips, sometimes uneven, of one tier of cells at terminus with small round bases enclosed within a sheath capsule $(8-20 \mu \mathrm{m}$ diam), with unfinished tips, when tall (FIG. 8E); most frequently with compound capitate and expanded tips, $8-15 \mu \mathrm{m}$ in diam (FIG. 8J) and with loose expanded bases, when 


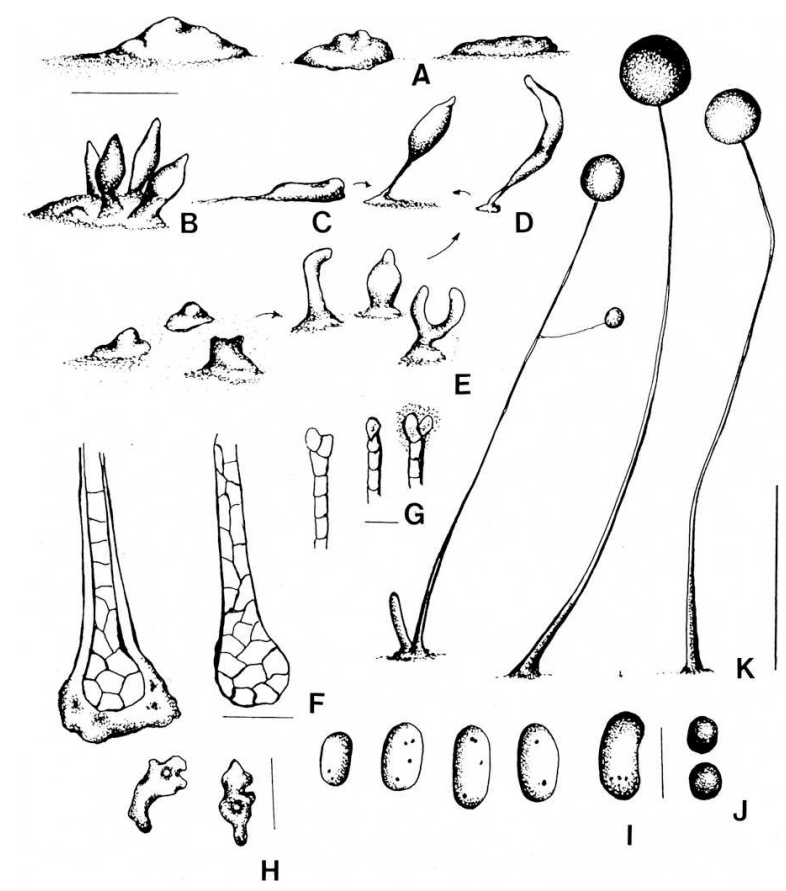

FIG. 7. Dictyostelium nanopodium. A Irregular moundlike aggregations. B,C. Early clustered (left) and migrating sorogens (right). D, E. Different shapes of late sorogens. F. Globoid to round bases. G. Simple to capitate tips. H. Myxamoebae. I. Elliptical spores with consolidated subpolar granules. J. Microcysts. K. Mature sorocarps. Bars: A-E = $0.2 \mathrm{~mm} ; \mathrm{F}, \mathrm{G}=15 \mu \mathrm{m} ; \mathrm{H}=10 \mu \mathrm{m} ; \mathrm{I}, \mathrm{J}=5 \mu \mathrm{m} ; \mathrm{K}=0.2 \mathrm{~mm}$.

small. Sori hyaline-white, globose to apiculate, 60$120 \mu \mathrm{m}$ diam. Spores oblong to elliptical, irregular, with sparse small granules but sometimes with prominent granules (FIGS. 6D; $8 \mathrm{~F}$ ), in a wide range of sizes, $4.5-8(-8.3) \times 2.0-4.5 \mu \mathrm{m}$, mostly $5-7 \times 3-$ $3.5 \mu \mathrm{m}$ (average $5.8 \times 3.0 \mu \mathrm{m})$. Aggregations: ample flattened streams or fine intervowen streams which anastomose (400-500 $\mu \mathrm{m}$ diam.), then a mound or a group of mounds may form a crown of early sorogens (FIGS. 6E, 8A). Sorogens develop rapidly and are short, papilla-shaped at first, then vermiform and curved, may migrate freely for some time, then they lift up, leaving behind the first formation of a lower sorophore (FIGS. 6F; 8B, C, D). Late sorogens are tall, sinuose and curled with prostrate lower sorophore. Myxamoebae may migrate out of the streak of bacteria.

Commentary. On hay infusion agar and below $20 \mathrm{C}$ sorogens rarely migrate and sorocarps are smaller and stouter.

Etymology: vermiformum, referring to the shape of early migrating sorogens.

Habitat and distribution. Soil-litter of the Yry-apú area (pH 6) Iguazú Regional Park, Misiones, Argentina.

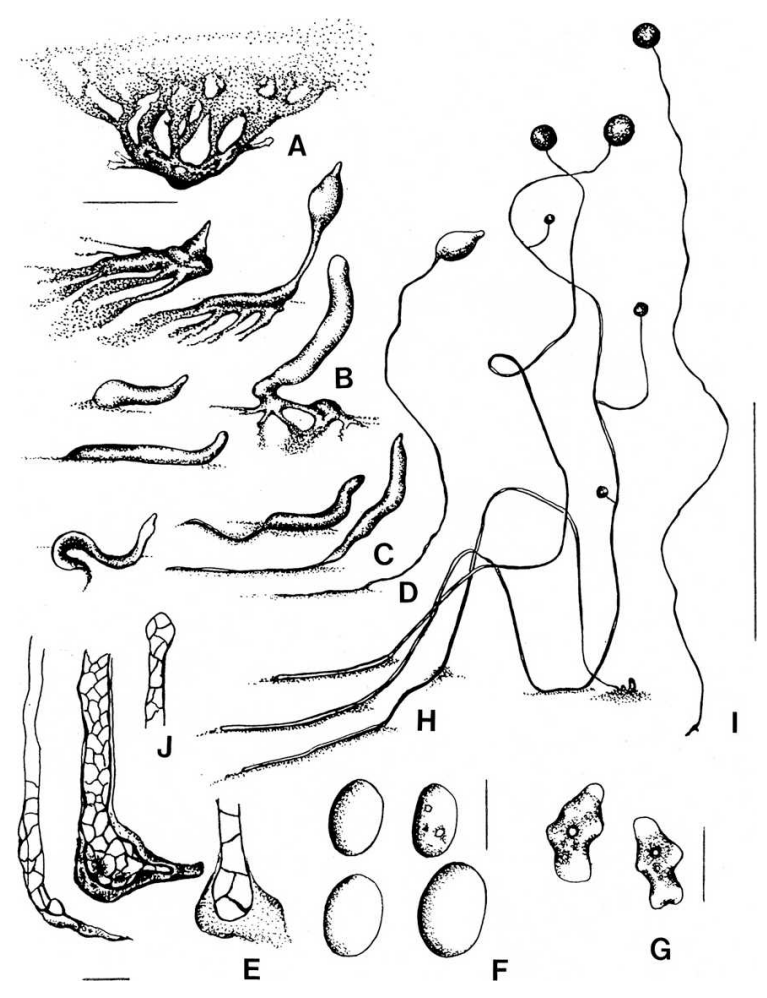

FIG. 8. Dictyostelium vermiformum. A-D. Sequence of development from ample flattened streamed aggregations (A) to papillate early sorogen (B) to vermiform (C) and migrating late sorogens (D). E. Expanded base and lower sorophore. F. Oblong to elliptical spores with sparse small granules. G. Myxamoebae. H, I. Mature sorocarps. J. Compound capitate tip. Bars: A-D $=0.2 \mathrm{~mm}$; $\mathrm{E}, \mathrm{J}=$ $20 \mu \mathrm{m} ; \mathrm{F}=5 \mu \mathrm{m} ; \mathrm{G}=15 \mu \mathrm{m} ; \mathrm{H}, \mathrm{I}=0.5 \mathrm{~mm}$.

Cultures examined. ARGENTINA, MISIONES: Iguazú Regional Park, Yry-apú trail, 25 28' S, 56 $1^{\prime}$ W, elevation $200 \mathrm{~m}$. Isolate from soil-litter, 15 Mar 2003, Cavender No. 10YA2, BAFC 1007 (HOLOTYPE).

\section{Polysphondylium arachnoideum Vadell et Cavender sp. nov. Figs. 6G-I, 9A-M.}

Sorocarpia culta in agaro nonnutricio cum E. coli ad 20-25 C, solitaria vel fasciculata remisse, prona vel erecta, interdum prostrata, aut parvula aut magna, leve phototropica, e 3 ad $15 \mathrm{~mm}$ longa. Sorophora non symmetrica, angularis adeo ut perfracta sunt. Praesertim sorophora supra bases, sinuosa et irregularia, unicellularia quid in speciem araneae telae, saepe sine sori, nata sunt. Bases claviformes, irregularia, (20-40 $\mu \mathrm{m}$ diam). Verticilli e 1 ad 20; internodiis brevius e 150 ad $350 \mu \mathrm{m}$. Nodae $2-4$ ramis, e 90 ad $230 \mu \mathrm{m}$ longa. Ramis grandis in angulo rectum e axis; dein curvae. Sorophora infra partes cum ramis e 200 ad $1000 \mu \mathrm{m}$, interdum verticillii. Sorophora infra apices saepe longissima, irregularia, e 100-1000 $\mu \mathrm{m}$ longa, angusta (1.5-4 $\mu \mathrm{m}$ diam). Sori terminales $40-$ 


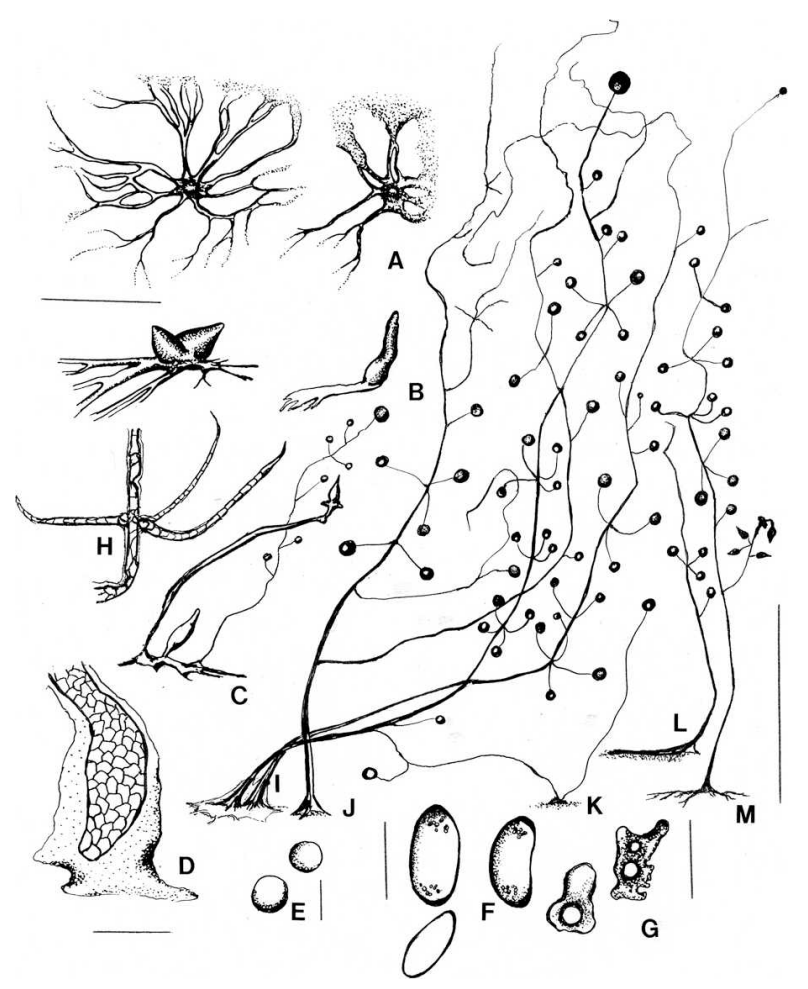

FIG. 9. Polysphondylium arachnoideum. A. Aggregation of the violaceum type. B Early sorogens. C. Early fusiform and late elongated sorogens. D. Clavate base. E. Microcysts. F. Elliptical spores with refractile unconsolidated polar granules and spore case. G. Myxamoebae. H. Detail of a whorl. I, J, K, L, M. Mature sorocarps. Bars: A-C. $=0.5 \mathrm{~mm}$; D $=$ $30 \mu \mathrm{m} ; \mathrm{E}=5 \mu \mathrm{m} ; \mathrm{F}=6 \mu \mathrm{m} ; \mathrm{G}=15 \mu \mathrm{m} ; \mathrm{H}=50 \mu \mathrm{m} ; \mathrm{I}-\mathrm{M}=$ $1 \mathrm{~mm}$.

$120 \mu \mathrm{m}$ in diam. et laterales $20-60 \mu \mathrm{m}$ in diam., globosi, albo-hyalini. Sporae e ellipticae ad reniformes, $5-8(-8.5) \times 3-4.5 \mu \mathrm{m}(\operatorname{dim} .6 .7 \times 3.7 \mu \mathrm{m})$; granulis non consolidatis polaribus, refractaria. Praecox sorogena ample, dein vermiformia. Provecta sorogena longissima et curva. Aggregationes ad classem "violaceum" pertinentes, 500-1000 $\mu \mathrm{mn}$. Myxamoebae breves, 8-11 $\times$ 4-6 $\mu \mathrm{m}$, saepe 2-3 grandis vacuolis. Microcystae praesentes, media magnitude $4 \mu \mathrm{m}$.

Sorocarps solitary to loosely clustered, erect to prone, sometimes prostrate, small to large, slightly phototropic, from 3 to $10-15 \mathrm{~mm}$ when prostrate, when cultivated on nonnutrient agar with $E$. coli at 20-25 C. Sorophores asymmetrical, with sharp changes of axis direction, uneven. Upper sorophores of one tier of cells, sinuose, producing delicate spiderweb-like trama, sometimes without sori (FIG. 9I-M). Bases clavate, irregular, 20-40 (FIG. 9D). Number of whorls varying from 1 to 20 , with internode distance of $150-350 \mu \mathrm{m}$, consisting of 2-4 branches of 90 $230 \mu \mathrm{m}$. Large branches in a whorl are at $90^{\circ}$ with respect to the sorocarp, then recurved (FIGS. 6I, 9H). Lower sorophore with branches of 200-1000 $\mu \mathrm{m}$, sometimes with secondary whorls. Terminal segment elongated and irregular, varying from 100 to $1000 \mu \mathrm{m}$, very thin $(1.5-4 \mu \mathrm{m})$. Terminal sori hyaline-white, globose, $40-120 \mu \mathrm{m}$ diam. Lateral sori 20-60 $\mu \mathrm{m}$ diam. Spores elliptical to reniform, 5-8 ($8.5) \times 3-4.5 \mu \mathrm{m}$ (average $6.7 \times 3.7 \mu \mathrm{m})$ with refractile unconsolidated polar granules (FIGS. 6G, 9F). Early sorogen expanded, then vermiform (FIG. 9C). Late sorogens very elongated and curved (FIG. 9C). Aggregation of the "violaceum" type (i.e., the initial primary aggregation divides into smaller secondary centers of aggregation), 500-1000 $\mu \mathrm{m}$. Streams are thin and elongated, sometimes ample at the edge of the aggregation (FIGS. 6H, 9A). Myxamoebae small, 8-11 $\times$ 4-6 $\mu \mathrm{m}$, generally with two large vacuoles (FIGS. 9G). Microcysts: $4 \mu \mathrm{m}$ on average (FIG. 9E).

Commentary. Size variation depends on both temperature and hydric conditions of the cultures in addition to the food supply. This species prevails over other dictyostelids in the Iguazú region.

Etymology: arachnoideum, referring to the production of a spider web-like terminal sorophores.

Habitat and distribution. Soil-litter of the Site I, Upper-Lower trail, Site II, Macuco trail and Yacaratia trail of the Iguazú National Park and in soils of the Yryapú area, site IV ( $\mathrm{pH}$ 6) Iguazú Regional Park, Misiones, Argentina. Also in Puerto Canoas, Iguazú National Park in Nov 1995. The species appears dominant in 3 sites of the Iguazú area, within the Regional and National Parks. (Vadell 2003).

Cultures examined. ARGENTINA, MISIONES: Iguazú Regional Park, Yry-apú trail, $25^{\circ} 28^{\prime}$ S, $56^{\circ} 1^{\prime} \mathrm{W}$, elevation $180 \mathrm{~m}$. Isolate from soil-litter, 17 Aug 1999, Vadell No. 1040YA7, BAFC 945 (HOLOTYPE). ARGENTINA, MISIONES: Iguazú National Park, Macuco trail, elevation $200 \mathrm{~m}$. Isolate from soil-litter, 15 Nov 2001, Vadell No. 1138M10, BAFC 946. ARGENTINA, MISIONES: Iguazú National Park, Yacaratia trail, elevation $200 \mathrm{~m}$. Isolate from soil-litter, 18 Nov 2001, Vadell No. 1148M15, BAFC 948.

\section{DISCUSSION}

The data obtained from Iguazú make possible a comparison of Neotropical dictyostelids from the Northern and Southern Hemispheres. Considerable dictyostelid data are available for Tikal National Park, Peten, Guatemala which is located in the Northern Hemisphere (Holmes 1991, Vadell 1993, Cavender 2005). Iguazú and Tikal have many similarities. Both are relatively pristine areas of subtropical seasonal rain forest. Tikal National Park is $200 \mathrm{~km}^{2}$ at latitude $17 \mathrm{~N}$ while Iguazú is $550 \mathrm{~km}^{2}$ at $25 \mathrm{~S}$. Both are surrounded by even larger areas of intact forest (Tikal $576 \mathrm{~km}^{2}$, Iguazú $670 \mathrm{~km}^{2}$ ). The area sampled at Tikal 
for dictyostelids was within $3 \mathrm{~km}^{2}$ and at Iguazú $4 \mathrm{~km}^{2}$.Both areas have fertile soils containing abundant organic matter although the soils at Tikal are derived from limestone while at Iguazú they are from volcanic rock. Mean annual temperature at Tikal is $24 \mathrm{C}$, at Iguazú $21 \mathrm{C}$. Annual rainfall at Tikal is $2000 \mathrm{~mm}$, at Iguazú $1700 \mathrm{~mm}$. Plant and animal diversity is high in both areas $(2000+$ plant species in both areas) and there are some moderate topographic changes providing some variations in moisture.

Thirty two species and varieties of dictyostelids have been isolated from Tikal, while twenty seven were found at Iguazú (both from 80-90 samples), also with a high degree of csm species richness. In addition to the seven new species reported here there are six new varieties of these existing species: Dictyostelium lavandulum, D. tenue, D. discoideum, D. macrocephalum, Polysphondylium asymetricum and Acytostelium aggregatum. The varieties differ from the described species in some important morphological feature, e.g. the variety of $D$. lavandulum (Raper and Fennell 1967) lacks the crampon base but is identical in other respects. Of these species Dicytostelium lavandulum, $D$. discoideum and $A$. aggregatum are not reported from Tikal. The first two occur in Costa Rica (Cavender and Raper 1968) while A. aggregatum was found in the Peruvian Amazon (Cavender 2005). Of the new species and varieties only the variety of $D$. macrocephalum (Hagiwara et al 1985) occurs at Tikal. This variety appears to be widespread in the Neotropics. There are, as a result, 15 species and varieties common to both Iguazú and Tikal: D. polycephalum, $D$. aureo-stipes, D. implicatum, D. tenue, D. coeruleostipes, D. macrocephalum, D. macrocephalum n. var., $D$. monochasioides, D. medusoides, D. purpureum, D. giganteum, D. mucoroides var. stoloniferum, Polysphondylium violaceum, $P$. asymetricum and $P$. colligatum. Therefore twelve species and varieties (44\%) at Iguazú are not found to date at Tikal or elsewhere in the Northern Hemisphere. Differences in community composition between Northern and Southern Hemisphere may indicate that there is different evolutionary history and/or different natural selection factors in the two hemispheres. Other recent data may support this hypothesis. In Tierra del Fuego and Patagonia, Argentina, six of the nine species isolated are not found in the Northern Hemisphere (Cavender et al 2005). Of 13 species from New Zealand four were not in the Northern hemisphere (Cavender et al 2002) while collections from Australia show that a large portion of the species are different from those of the Northern Hemisphere (Landolt et al 2005).

In addition to the species differences there are some differences in the morphologies of the two
Hemispheric groups. For example, the bases of Southern Hemisphere species are more likely to be surrounded in a dense matrix of slime. The sori are also more likely to contain dense slime that does not allow the spores to disperse in water. The most striking difference noted however, is in the polar granule $(\mathrm{PG})$ characteristic of spores. There are more species with polar spore granules in the Southern Hemisphere. For example, the percentage of PG+ species in Ohio is $42 \%$ (Cavender and Vadell 2006), in Tikal 58\% (Cavender 2005), and in Iguazu 64\%. The percentage of PG+ species in Australia(unpublished data) appears to be even higher at $68 \%$. Recent molecular studies of the SSU rRNA and alpha-tubulin gene in the described dictyostelid species and the construction of a phylogenetic tree (Schaap et al 2006) shows that the PG+ species are closer to the root of the tree. The greater number of $\mathrm{PG}+$ species in the Southern Hemisphere may indicate that early evolution of the dictyostelids took place there.

The seven new species described exhibit some new and interesting morphological features. Dictyostelium dichotomum, which is intensely yellow in pigmentation not unlike D. mexicanum (Cavender et al 1981) and D. granulophorum (Vadell et al 1995), constructs a fruiting body by means of repeated dichotomous branching. Only a single dichotomous branching has been described previously for D. bifurcatum (Cavender 1976a). Polysphondylium arachnoideum produces elongated sorophore tips not unlike those of $P$. candidum (Hagiwara 1973b) however it has a much greater tendency to do this forming a web-like structure in aggregate. Dictyostelium menorah is unusual because of the irregular branching pattern, but always resembling a candelabrum. Sometimes a number of short branches are unilateral, producing a structure much like a menorah in appearance. It was isolated with what appears to be a symbiotic Actinomycete associate. Dictyostelium macrocarpum has relatively large mounded pseudoplasmodia, a type not seen before in dictyostelids but now discovered in this species and at least one other undescribed species from Australia (Landolt et al 2005). Dictyostelium brevicaule was first described by E. W. Olive (1901). Emphasis was placed in the description on the relatively short stalk in respect to the size of the sorus. Although the holotype was lost this feature is well expressed by the new variety we describe. Dictyostelium vermiformum has two features which set it apart, the elongated sorogens which tend to produce prostrate lower sorophores not unlike those of D. sphaerocephalum (Raper 1984) and the small, narrow PG+ spores. Of all the species $D$. nanopodium is the most diminutive. It is noteworthy because of its very small size, approaching $D$. deminutivum (Ander- 
son et al 1968) in stature, although there are differences from this species in the size and shape of the spores as well as the sorocarps.

\section{AKNOWLEDGMENTS}

The authors wish to thank: Amelia Marroquín, Francisco Hita and Mark Garland for the help in the Latin diagnoses; Parques Nacionales Argentinos as well as the Mbya Guaraní aboriginal community for their guidance within the Yry-apú area and the Iguazú Regional Park; Museo de Historia Natural "Dr. Ricardo S. Vadell”, CC 16- Suipacha- Provincia de Buenos Aires, Argentina for support and Dr. Jorge E. Wright. The research was supported in part by NSF Grant DEB-0316284.

\section{LITERATURE CITED}

Anderson JS, Fennell DI, Raper KB. 1968. Dictyostelium deminutivum, a new cellular slime mold. Mycologia 60: 49-64.

Bailby E. 1995. The Iguaçu Falls. UNESCO Courier. Vol. 48 1:40-43.

Bonfils CG. 1970. Los recursos edáficos. In: IX Jornadas Argentinas de Botánica. Las Ciencias Naturales en el Nordeste argentino y el Este del Paraguay. A.L. Cabrera (Dir.) Bol. Soc. Arg. Bot. V. XI Sup.: p 103-109.

Bonner J T. 1947. Evidence for the formation of cell aggregates by chemotaxis in the development of the slime mold Dictyostelium discoideum. Jour. Exptl. Zool. 106:1-26.

Cabrera AL, Willink A. 1982. Biogeografia de America Latina. Serie Biología. Monografía 13 OEA: Washington D.C. 122 p.

Cavender JC. 1969. The occurrence and distribution of Acrasieae in forest soils II. East Africa. Amer. J. Bot. 56: 993-998.

— 1976a. Cellular slime molds of Southeast Asia. I Description of new species. Am. J. Bot. 63:60-70.

- 1976b. Cellular slime molds of Southeast Asia. II. Occurrence and distribution. Amer. J. Bot. 63:71-73.

- 1996. Dictyostelid cellular slime molds from the Amazon basin of Perú. Inoculum, 471996 MSA (abstracts) 5 p.

- 2005. Neotropical dictyostelids-Mexico and beyond. (Abstr) ICSEM 5, Tlaxcala, Mexico, p 15-16.

—- Raper KB. 1965. The Acrasieae in nature. I. Isolation. Amer. J. Bot. 52:294-296.

1968. The occurrence and distribution of Acrasieae in forests of subtropical and tropical America. Amer. J. Bot. 55:504-513.

,-- , Norberg AM. 1979. Dictyostelium aureo-stipes and Dictyostelium tenue: new species of the Dictyosteliaceae. Amer. J. Bot. 68:207-217.

—_, Stephenson SL, Landolt JC, Vadell EM. 2002. Dictyostelid cellular slime moulds in the forests of New Zealand. New Zealand J. Bot. 40:235-264.

— Vadell EM. 2000. The genus Acytostelium. 2000. Mycologia 92(5):992-1008. $\longrightarrow$ - - 2006. Cellular slime molds of Ohio. Ohio Biological Survey, Columbus.

$\longrightarrow$ - Stephenson SL. 2005. Dictyostelid Cellular Slime Molds of Patagonia and Tierra del Fuego. (Abstr.) ICSEM 5. Tlaxcala, México, p 14.

—, Worley AC, Raper KB. 1981. The yellow pigmented Dictyostelia. Amer. J. Bot. 68:373-382.

Dimitri MJ. 1974. La flora arbórea del Parque Nacional Iguazú. Anales de Parques Nacionales. XII. 181.

Hagiwara H. 1973a. Enumeration of the Dictyosteliaceae. Mycological reports from New Guinea and the Solomon Islands. Bull. Natl. Sci. Museum 16:493-497.

. 1973b. The Acrasiales in Japan. II. Rept. Tottori Mycol. Inst. 10:591-595.

— Y Yeh Z-Y, Chien C-Y. 1985. Dictyostelium macrocephalum, a new dictyostelid cellular slime-mold from Taiwan. Bull. Natl. Sci. Mus,. Tokyo, Ser B 11:103108.

Holmes MT. 1991. Seasonal variations in the distribution of dictyostelid cellular slime molds at three sites at Tikal, Guatemala and their taxonomy. [Master's Thesis]. Ohio University: Athens, USA, 170 p.

Landolt JC, Stephenson SL. 1991. Cellular slime molds from tropical rain forest of eastern Perú. Crypt. Bot. 2/3: 258-261.

— Cavender JC, Vadell EM, Stephenson SL. 2005. Dictyostelid cellular slime molds of Australia.(Abstr.) ICSEM 5, Tlaxcala, Mexico, p 54.

Olive EW. 1901. A preliminary enumeration of the sorophoreae. Proc. Amer. Acad. Arts Sci. 37:333-244.

Olive LS. 1975. The Mycetozoans Academic press: New York, $293 \mathrm{p}$.

Piaggio MJ. 1989. Distribution of dictyostelid cellular slime molds in two grazing land soils in Uruguay. Cryptogamie 10:173-178.

Raper KB. 1984. The Dictyostelids Princeton University Press: Princeton, NJ, 453 p.

— Fennell DI. 1967. The crampon-based Dictyostelia. Amer. J. Bot. 54:515-328.

Schaap P, Winckler T, Nelson M, Alvarez-Curto., Elgie B, Hagiwara H, Cavender J, Milano-Curto A, Rozen D, Dingermann T, Mutzel R, Baldauf S. 2006. Molecular phylogeny and evolution of morphology in the social amoebas. Science 314:661-663.

Stephenson SL, Landolt JC, Mitchell D, Roody W. 1995. Dictyostelid cellular slime molds of New Zealand. In: Lado C, Hernández JC., eds. Abstract Volume of the Second International Congress on the Systematics and Ecology of Myxomycetes I: 120 .

- - Laursen GA, Seppelt RD. 1998. Dictyostelium mucoroides from subantarctic Macquarie Island. Mycologia 90:368-371.

Vadell EM. 1993. Taxonomy, ecology and karyotypes of the cellular slime molds of Tikal, Guatemala. [Master's Thesis]. Ohio University: Athens, USA, 213 p.

—. 2000. Dictiostélidos (Eumycetozoa) de suelos de Punta Lara, Provincia de Buenos Aires, Argentina. Rev. Arg. Microbiol. 32:89-96.

— 2003. Contribución a la Sistemática y Ecología de los Dictiostélidos del Parque Nacional Iguazú, Mis- 
iones, Argentina. [Doctoral dissertation]. Departamento de Biodiversidad y Biología Experimental Facultad de Ciencias Exactas y Naturales, Universidad de Buenos Aires: Buenos Aires, Argentina, 260 p.

, Cavender JC. 1995. Dictyostelid cellular slime molds from forest soils of the Iguazú Falls and the Jesuitic Missions Ruins of Argentina. In: Lado C, Hernández JC., eds. Volume of the Second International Congress on the Systematics and Ecology of Myxomycetes (ICSEM 2) 1:110 (abstract).

- - 1998. Polysphondylium from forest soils of Tikal, Guatemala. Mycologia 90:715-725.

- Holmes MT, Cavender JC. 1995. Dictyostelium citrinum, D. medusoides and D. granulophorum: Three new members of the family Dictyosteliaceae from the forest of Tikal, Guatemala. Mycologia 87(4):551-559. 